\title{
Lírica contemporânea e tradição poética: topoi clássicos em poemas de Érico Nogueira, Fabrício Marques e Paulo Henriques Britto
}

\section{Contemporary Lyric and poetic tradition: classic topoi in poems by Érico Nogueira, Fabrício Marques and Paulo Henriques Britto}

Rafael Quevedo

Universidade Federal do Maranhão, São Luís, Maranhão / Brasil rafaelquevedo2001@yahoo.com.br

Resumo: Este artigo analisa poemas de Paulo Henriques Britto, Érico Nogueira e Fabrício Marques sob a perspectiva da investigação tópica. Para isso, propõe um reajuste da metodologia em questão a fim de tornar exequível seu emprego em um corpus contemporâneo.

Palavras-chave: investigação tópica; poesia contemporânea de língua portuguesa; topoi líricos.

Abstract: In this article I analyze poems by Paulo Henriques Britto, Erico Nogueira and Fabrício Marques from the perspective of topical research. For this, I propose an adjustment of the methodology in question in order to make possible its use in contemporary corpus.

Keywords: topical research; contemporary poetry in Portuguese language; lyrical topoi.

Recebido em: 17 de janeiro de 2017.

Aprovado em: 14 de junho de 2017. 
Obras pertencentes à atual poesia de língua portuguesa têm apresentado uma prática que, muito embora não configure nenhuma linha de força do contemporâneo, tampouco se pode dizer que se trata de um traço casual ou fortuito. Trata-se do cultivo de vários topoi oriundos da poesia tradicional (clássica e medieval).

Nos estudos do gênero lírico, os topoi ou lugares-comuns constituem, grosso modo, esquemas expressivos mais ou menos flexíveis que, consagrados pela tradição, são atualizados em diferentes momentos literários. Cultivados fecundamente até o século XIX, passam por um sistemático processo de abandono, mercê da campanha romântica de demolição da tradição clássica que se estende até o modernismo. A partir de então, o exercício da criação poética baseada em antigos topoi passa a ser mais eletivo, praticado episodicamente, em clave paródica ou "erudita".

Os consagrados estudos de Segismundo Spina (no Brasil) e do alemão Ernst Robert Curtius, por sua vez, atestam a legitimidade do trabalho crítico baseado na investigação tópica, muito embora tal método tenha se limitado às épocas literárias em que a imitatio poética proporcionava condições para a proliferação dos lugares-comuns líricos. No âmbito do comparatismo literário, a aplicação da investigação tópica em um corpus lírico contemporâneo levanta importantes problemas relativos aos elos da poesia atual com a tradição, entre os quais o que se refere à possibilidade da permanência residual da tradição na contemporaneidade ou, ainda, à hipótese de que novos lugares-comuns tenham sido forjados a partir da reelaboração dos antigos.

Para o emprego da investigação tópica em um corpus lírico contemporâneo proponho, portanto, uma outra angulação metodológica, tendo em vista dois postulados basilares do trabalho de Curtius que incidem diretamente sobre o conceito de topos, que são: as noções de unidade literária e de continuidade da tradição.

Se todo o grande escopo do monumental Literatura europeia e Idade Média latina consistiu em atestar a unidade literária da Europa como tendo se estabelecido a partir de um legado cultural proveniente da Antiguidade greco-latina que atravessou o medievo até ingressar nas literaturas nacionais "modernas", o topos, por sua vez, é entendido, na obra em questão, como um elo numa cadeia de transmissão chamada tradição literária. É nesse sentido que, em uma investigação assentada nesses pressupostos, há sempre o risco, com relação ao qual o estudioso precisa estar sempre precavido, de se confundir um topos (índice de 
continuidade, de transmissão da tradição) com um caso de "poligenesia literária" (condições culturais similares que ajudam a forjar formas expressionais semelhantes). Foi o que observou Segismundo Spina acerca da análise feita por Curtius do tópico do "mundo às avessas":

O exame da reprodução tópica pode conduzir-nos à errônea suposição de que se trata de uma continuidade histórica do tópico, quando muitas vezes pode acontecer que se trata de casos de poligenesia literária. Alhures já estudamos o tópico do "mundo subvertido", em que procuramos mostrar que Curtius deve ter feito confusão quando misturou nesse outros tópicos, como o do florebat olim... e o da seriação de impossibilia (adynata) (SPINA apud CURTIUS, 2013, p. 19).

Se o que está em exame passa a ser a produção poética de uma época cujos elos com a tradição não são mais de continuidade, mas de revisitação; em que o poeta não se vê mais ligado à necessidade de legitimação da sua arte por meio da imitação das convenções consagradas; tendo em vista essa conjuntura em tudo diversa, forçoso é, portanto, que a presença de topoi tradicionais num poema contemporâneo não seja vista como um indício nem de continuidade da tradição, tampouco de unidade literária, mas sim como uma espécie de intertexto por meio do qual presente e passado se interceptam proporcionando deslocamentos de sentido decorrentes dos diferentes contextos de produção em que são praticados os lugares-comuns em questão.

É nesse sentido que o risco anteriormente mencionado (o de se confundir tópica com poligenesia literária) deixa de existir, uma vez que se parte da condição aceite da descontinuidade da tradição e, consequentemente, o topos deixa de ser visto como elo cultural ou índice de unidade para ser acatado como expediente intertextual.

Casos há em que, em determinados poemas contemporâneos, não se observa o topos em sua integridade estrutural, mas sim em vestígios de sua constituição (uma metáfora pronta, uma fórmula linguística consagrada, um esquema de pensamento), indicativos, portanto, de que o poeta não colheu deliberadamente do acervo da tradição o topos em questão (ou, caso tenha feito, procurou dissimulá-lo), mas que "topou" com ele, para usar aqui o jogo de palavras de um poema de Affonso Romano de Sant'anna: "Forma melhor de escrever é ler e ler nos outros 
/ o que pensamos ser só nosso e é de tantos, há tanto, / que nada de novo existe, topos com que topo eu, / lugar-comum de tantos tipos que me reescreveram" (SANT'ANNA, 1999, p. 107).

Como se pode observar, a premissa que subjaz a essas considerações é a de que a produção contemporânea, dentro do gênero lírico, continua a manter, necessariamente, algum tipo de relação com o que se escreveu no passado. No que diz respeito ao nível da intencionalidade do autor essa relação pode ser premeditada ou não e, no tocante ao tipo de elo mantido com o passado, ele pode se dar tendo em vista uma aproximação com a tradição ou uma contravenção a ela, mas nunca o poema estará totalmente à margem ou alijado dela. À pergunta sobre em que medida um autor de 2017 estaria irremediavelmente em contato com a tradição se, suponhamos, ele nem sequer tenha tido um contato com ela, proponho uma resposta um tanto hipotética, a saber, a de que ao se expressar dentro de um determinado gênero, o autor se conecta com determinados campos experienciais com os quais os poetas mais longínquos inevitavelmente se ocuparam. Exemplo: a experiência humana com relação à própria finitude. Com isso quero dizer que o mais desprevenido dos poetas, ao tratar de um motivo como esse, aterrissa num terreno já semeado por várias e remotas vozes, cabendo a ele colocar a sua.

Isso posto, o que adiante será apresentado consiste no exame de poemas que, ou atualizam deliberadamente alguns topoi relacionados à passagem do tempo ou retomam o mesmo conteúdo sem se valerem do esquema retórico que tipifica a forma consagrada do topos. Nesse sentido, o que aqui se propõe é que, na abordagem dos deslizes de sentido resultantes do deslocamento contextual em jogo na atualização do topos (ou de alguns de seus traços), não apenas a relação da lírica atual com a do passado seja posta em questão, mas também aspectos que dizem respeito à própria relação da poesia com a contemporaneidade sejam evidenciados, gesto de algum modo inspirado no famoso ensaio de Giorgio Agamben intitulado "O que é o contemporâneo", especialmente no trecho em que diz:

Pertence realmente ao seu tempo, é verdadeiramente contemporâneo, aquele que não coincide perfeitamente com este, nem está adequado às suas pretensões e é, portanto, nesse sentido, inatual; mas, exatamente por isso, exatamente através desse afastamento e desse anacronismo, ele é capaz, mais do que os outros, de perceber e de apreender o seu tempo (AGAMBEN, 2009, p. 58). 
A experiência do eu diante de sua própria finitude, portanto, faria parte do repertório de experiências que teriam servido de base para a expressão lírica e isso de fato se deu com a proliferação de vários topoi que tratam da percepção humana da temporalidade, entre os quais: a "efemeridade da vida" e o carpe diem, que abordam centralmente a passagem do tempo; o "convite amoroso" e a "profecia ameaçadora", que conciliam a tópica do tempo com propósitos eróticos; e o exegi monumentum, que trata do poder da palavra poética de vencer a transitoriedade do tempo. Neste artigo, trato da tópica da efemeridade e do carpe diem em poemas de Érico Nogueira e Fabrício Marques e, em seguida, parto para o topos do exegi monumentum e, para abordá-lo, valho-me de dois poemas de Paulo Henriques Brito, extraídos do seu livro de 2012, Formas do nada.

Segundo Francisco Achcar, as origens da tradição da tópica da efemeridade se reportam às epopeias homéricas, mais precisamente à Ilíada, que teria inaugurado, com o símile das "folhas caídas", a prática de se recorrer a um elemento comparativo da natureza para se falar da degeneração das gerações humanas que perecem e cedem lugar a outras: "Ó Tideide, ardoroso de ânimo, por que/perguntas minha origem? Símile à das folhas,/a geração dos homens: o vento faz cair/as folhas sobre a terra. Verdecendo, a selva/enfolha outras mais, vinda a primavera. Assim/a linhagem dos homens: nascem e perecem" (HOMERO, 2003, p. 241).

Já na lírica grega, com o poeta Simônides (sec. VI-V a.C.), o símile de origem homérica reaparece associado, pela primeira vez, à exortação hedonista. O fragmento, traduzido em decassílabos por Aluízio de Faria Coimbra é o que se segue:

O que mais belo disse o homem de Quios, "Os homens passam como as folhas passam", muito poucos mortais, de quantos o ouvem, o imprimem n'alma. Agita-os a esperança, que dos moços no peito sempre viça. Ao que orna a flor gentil da juventude, o ânimo inconsequente muitos sonhos nutre impossíveis. Nem sequer lhe ocorre que há de um dia morrer, tornar-se velho ou feri-lo a doença. Loucos, esses!

Não veem quão breve a quadra e curta a vida! Mas tu que sabes estas cousas, a alma com virtudes dispõe para a velhice. (SIMÔNIDES apud ACHCAR, 1994, p. 65) 
O tom moralista imposto por Faria de Coimbra na tradução dos dois últimos versos obnubila um importante aspecto na evolução da tópica: "A fusão de exigência de lucidez e conclamação ao prazer [...] constante na lírica do carpe diem, na qual o hedonismo é sempre apresentado como resultante da lógica da consciência da efemeridade; daí que ele deva distinguir-se da inconsequência juvenil, inconsciente dos limites da existência" (ACHCAR, 1994, p. 67). A tradução literal dos referidos versos, feita pelo próprio Achcar, torna esse aspecto mais evidente: "Mas tu, sabendo destas coisas relativas ao termo da vida, dispõe-te a conceder prazeres a tua alma" (ACHCAR, 1994, p. 65).

Em Horácio, o topos assume a forma definitiva que tanto influenciará a tradição lírica de língua portuguesa, com o eterno verso "carpe diem, quam minimum credula postero", pertencente à famosa "Ode a Leucônoe". Eis algumas das versões que o verso ganhou em vernáculo: "Logra o presente e no porvir não cansa" (André Falcão de Resende) (ACHCAR, 1994, p. 230); "O dia de hoje colhe, e a mínima / No dia de amanhã confiança escores" (Filinto Elísio) (ACHCAR, 1994, p. 231); "Aproveita o presente, e não confies / Crédula no Futuro" (José Agostinho de Macedo) (ACHCAR, 1994, p. 231); "Ínvida a idade foge: colhe o dia / Do de amanhã mui pouco confiando" (Elpino Duriense) (ACHCAR, 1994, p. 232); "Doira as horas que tens, vive bem hoje, / No porvir não te fies" (Marquesa de Alorna) (ACHCAR, 1994, p. 232); "Desfruta o dia de hoje, acreditando / o mínimo possível no amanhã" (Péricles E. da Silva Ramos) (ACHCAR, 1994, p. 233); "curte o dia / desamando amanhãs" (Augusto de Campos) (ACHCAR, 1994, p. 234); "pega este dia / crer no próximo / não vale um nihil" (Paulo Leminski) (ACHCAR, 1994, 235).

Isso posto, apresento alguns poemas representativos da lírica contemporânea de língua portuguesa que abordam a temática discutida.

Ficando tarde

Estou ficando tarde. E o tempo

vai carpindo antes do tempo

rugas de cansaço e lucidez.

Com ar de melancolia

(Estou ficando tarde)

percorre o rosto um sorriso. 
As horas se gastam, amarelam como quando a vida arde -ó albor - na pele, sem aviso.

(MARQUES apud DANIEL; BARBOSA, 2002, p. 151).

O poema de Fabrício Marques concilia com concisão e simplicidade um impasse da vida que consiste na conquista tardia da lucidez (sabedoria) quando a juventude já ficou para trás. Desse modo, no mesmo rosto onde se rasgam as rugas, o sorriso de alegria confina com a expressão da melancolia. Esse amarelecer na pele, despontar de uma fase tardia da vida, lembra a luz de uma outra, dos tempos de alvorada em que a vida ardia. O poema tem como força motriz a sonoridade do 'ar' que atravessa todos os versos como a ecoar a sílaba tônica de tarde (Tarde / carpindo / ar / horas / amarelam / arde / albor) e a também recorrente alusão ao contínuo da vida, sugerido pelo gerúndio de "ficando" que se espraia nos vocábulos: "tempo", "carpindo", "ficando", “cansaço", "melancolia" e "quando". Juntas, essas duas recorrências perseveram foneticamente a ideia de "estou ficando tarde" ao longo de todo o poema.

Pode-se dizer que esse poema possui índole clássica, pela serenidade com que o eu lírico acolhe seu "entardecer": melancólico, porém sorridente ante o amarelecer da vida. O padrão cíclico de tempo não serve, contudo, como referência de que os tempos vêm e vão. Tratase de um entardecer que sucede um tempo que foi de alvorecer e que antecede a noite que logo chegará. Não se dirige a uma segunda pessoa, não exorta nem admoesta, portanto, mas produz em nós "a impressão de um contato reservado com o poeta" (ACHCAR, 1994, p. 47) sobre a qual fala Francisco Achar ao acusar o traço distintivo do gênero lírico.

Érico Nogueira, poeta de influência reconhecidamente clássica, mas que não deixa, contudo, de impostar uma dicção mais despojada, no que assume o pertencimento a seu próprio tempo, parece estar sempre preocupado em chegar a um conúbio entre tradição e contemporaneidade. O poema abaixo seria, a meu ver, um exemplar de tal projeto poético.

\section{Vésperas}

As folhas já se foram há certo tempo, há certo frio rochoso nas escarpas, parecem vir de lá dos quintos certas marcas que se decifram, ou algo assim, no vento. 


\begin{abstract}
A hora foi-se, a teu redor é tudo opaco; é tudo quase assim-assado, é um fiasco que nem sequer o que é consegue vir a ser; retesa a sombra, ou deixa-te escorrer.

(NOGUEIRA, 2008, p. 15)
\end{abstract}

Logo de início, no primeiro verso da primeira estrofe, que se encerra com a palavra tempo, o poema recupera a referência, de procedência homérica, das "folhas", assinalando a temática central do poema, que se vê reforçada por outras expressões ao longo dos versos ("a hora foi-se" e "deixa-te escorrer", por exemplo). A situação comunicacional encenada pelo poema: um eu que se dirige a uma segunda pessoa, indicando a situação em que ela se encontra ("a teu redor é tudo opaco") e, ao final, os caminhos que o sujeito lírico aponta como soluções para a situação diagnosticada ("retesa a sombra, ou deixa-te escorrer") definitivamente atualizam o esquema da poesia lírica tradicional, sobretudo aquela em que o carpe diem ou as outras tópicas do tempo (algumas vezes associadas ao amor) se fazem presentes. A temática do tempo, a situação comunicacional, a métrica adotada (4 decassílabos, sendo um sáfico e os outros três heroicos e 4 dodecassílabos) e o esquema rímico (abba, aabb) asseguram a filiação do poema à tradição lírica. Vejamos outros aspectos, agora no campo imagético/semântico.

A primeira estrofe consiste, basicamente, na formulação de uma situação de transitoriedade e de declínio reforçados por: folhas que se foram; escarpas (que são declives muito íngremes causados por erosão, por força da ação do tempo e dos agentes naturais) e, por fim, o vento que, na origem histórica da metáfora, é o responsável por arrastar as folhas consigo. Até aqui, ou talvez ainda se acrescentássemos também o último verso do poema, já estaria formado o esquema típico da lírica simposial antiga a que pertence o topos do carpe diem: "[...] situação dialógica, imagens da efemeridade e sentido deliberativo [...], ou seja, injunção ou sugestão de determinado curso de ação ou atitude existencial" (ACHCAR, 1994, p. 70).

A segunda estrofe, por sua vez, dá continuidade à descrição da transitoriedade do tempo, mas acrescenta a esse sentimento um outro que é o da constatação pessimista do contexto no qual se situam ficcionalmente o sujeito lírico e seu interlocutor. "Tudo opaco", "tudo quase assimassado" e "é um fiasco" seriam os termos dessa constatação que, a meu ver, poderia ser interpretada da seguinte maneira. O presente seria marcado por um momento: 1) de trevas ou obscurantismo, pois "opaco" 
significa tanto o que é sombrio por não permitir a passagem de luz, quanto, por extensão, o que é incompreensível, obscuro. 2) de mesmice ou imutabilidade indicada pela expressão "assim-assado" e 3) de "resultado desastroso ou insatisfatório, êxito desfavorável, insucesso, fracasso" que é o significado da palavra fiasco segundo o dicionário Antônio Houaiss.

Surge, portanto, do bojo de um poema que trata da efemeridade, outro topos de longa tradição: o do "desconcerto do mundo". Carlos Felipe Moisés, poeta e crítico literário paulista, diz que o "desconcerto do mundo" é a expressão do "mundo em desordem, palco de absurdos e desatinos em que tudo semelha ter perdido o rumo certo, saindo para fora dos eixos: tema antiquíssimo, tradição que remonta aos primeiros escritores gregos e latinos." (MOISÉS, 2001, p. 43). Segundo Segismundo Spina, em seu Do formalismo estético trovadoresco, para que o topos do desconcerto (ou do "mundo às avessas") se afirme enquanto tal, a mera descrição da decadência de uma época não é suficiente. Para ele, “[...] em geral, o que está na base deste tópico é a expressão de um descontentamento ou daquele que, desprezado pela mulher amada ou vítima do 'amor falso', acredita que tudo pode acontecer; ou o descontentamento com as coisas do mundo contemporâneo [...]" (SPINA, 2009, p. 103).

Além dessas possibilidades, o poema de Erico parece conter uma abordagem do problema da criação poética na contemporaneidade que estaria sendo avaliado, também negativamente, dentro da conjuntura de fiasco e mesmice anteriormente caracterizada. Chego a essa suposição por dois caminhos que se entrecruzariam. Se estou certo, o penúltimo e o último versos da primeira estrofe ligam-se tematicamente ao penúltimo e ao último da segunda estrofe no seguinte sentido: se for possível ler as "certas marcas" que "parecem vir lá dos quintos" e que se "decifram, ou algo assim, no vento" como a corrente da tradição que não chega integralmente ao tempo presente, mas sim em fragmentos, indícios que requerem um tipo difícil de apropriação e/ou decodificação (daí a hesitação do "algo assim" logo após o verbo decifrar); portanto, seguindo tal possibilidade interpretativa, o verso "que nem sequer o que é consegue vir a ser" expressaria, também, desde uma clave fornecida pela Antiguidade Clássica, o próprio fazer poético. Refiro-me à conhecida conceituação de poesia fornecida por Aristóteles, na Poética, mais especificamente quando o estagirita traça as fronteiras entre a poesia e a história, dizendo ser aquela mais filosófica que esta justamente porque o poeta não lida, como o historiador, com o "o que é”, mas com o "poder 
ser". Desse modo, o que o eu lírico estaria dizendo é que o tempo em que ele vive seria de tal modo sombrio, estagnado e malogrado que nem sequer a poesia se faria mais possível.

Entro, por essa via, no tema da reflexão da poesia feita pela própria poesia. Para tanto, tomo como ponto de partida o poema "Circular" de Paulo Henriques Britto.

\section{CIRCULAR}

Neste mesmo instante, em algum lugar, alguém está pensando a mesma coisa que você estava prestes a dizer.

Pois é. Esta não é a primeira vez.

Originalidade não tem vez neste mundo, nem tempo, nem lugar. O que você fizer não muda coisa alguma. Perda de tempo dizer

o que quer que você tenha a dizer.

Mesmo parecendo que desta vez algo de importante vai ter lugar, não caia nessa: é sempre a mesma coisa.

Sim. Tanto faz dizer coisa com coisa ou simplesmente se contradizer. Melhor calar-se para sempre, em vez de ficar o tempo todo a alugar todo mundo, sem sair do lugar, dizendo sempre, sempre, a mesma coisa que nunca foi necessário dizer. Como faz este poema. Talvez. (BRITTO, 2012, p. 12)

O poema "Circular" caracteriza, sob um aspecto em especial, a condição do poeta contemporâneo marcado pela profunda consciência da perda de certos referenciais que antes orientavam a criação de poesia. Refiro-me ao fator da novidade como motor da arte, relativamente estranho aos séculos de poesia tradicional marcadamente imitativa.

O título do poema citado alude a essa nova conjuntura. No lugar de um traço retilíneo por meio do qual as balizas temporais de passado e 
futuro podem ser demarcadas, tem-se aquilo que Linda Hutcheon (1991), referindo-se a outro aspecto da pós-modernidade, chamou de "circo com vários picadeiros", ou seja, um espaço de coabitação de manifestações artísticas díspares sem que uma pretenda impor sua verdade sobre a outra, como se dava na época das vanguardas.

Contudo, em relação ao todo do poema, o título aponta ainda para a ideia de que toda ação (e também toda enunciação) é vã. "Circular" sugeriria imobilidade, no sentido de que o que for feito/dito, não produzirá um deslocamento, mas ao final, voltará ao mesmo ponto de partida. Tal interpretação também está associada à questão da contemporaneidade artística, como mostra com bastante eloquência e concisão o conhecido poema "Pós-tudo", de Augusto de Campos, no qual é possível constatar o mesmo paradoxo enunciado pelo poema de Britto, a saber, a insistência da poesia em dizer, mesmo quando o dizer não serve para nada. No poema de Britto, a mensagem de que é melhor calar-se entra em contradição com a própria existência do poema que é a manifestação de uma voz.

Ao que parece, uma tópica sobre a "inutilidade da poesia" parece não ter precedente na tradição. Um ponto de vista contrário, na verdade, serviu de fundamento para o topos horaciano do exegi monumentum cujo conteúdo assinala o poder da poesia de sobreviver à passagem do tempo, imortalizando tanto o autor quanto o objeto do seu canto. A expressão que designa o topos se deve ao modo como Horácio formulou a perenidade da poesia, alegando que, ao escrever seu poema, erigiu um monumento "mais duradouro do que o bronze,/e mais alto do que as decaídas, régias Pirâmides". Cito apenas um trecho do conhecido poema horaciano:

Erigi monumento mais perene

do que o bronze e mais alto do que a real

construção das pirâmides, que nem

as chuvas erosivas, nem o forte

Aquilão, nem a série inumerável

dos anos, nem a dos tempos corrida

poderão, algum dia, derruir.

Não morrerei, de todo; parte minha

à própria morte não será sujeita:

eu, sempre jovem, crescerei, enquanto, com virgem silenciosa, o Capitólio

suba o pontífice [...]

(HORÁCIO, 2003, p. 141). 
No entanto, ao que tudo indica, a impressão do caráter "circular" da linguagem (no sentido de que as mesmas coisas sempre retornam quando pensamos emitir enunciados originais), pelo menos na poesia, não foi algo totalmente estranho ao mundo antigo, como se faz perceber na seguinte passagem de Tertuliano: "multicolor, de várias cores, versicolor, nunca a mesma, mas sempre outra, embora sempre a mesma quando outra, tantas vezes enfim mudando-se quantas movendo-se". (TERTULIANO apud ACHCAR, 1994, p. 32) ou nesta de Baquílides: "de um poeta [vem] o outro, no passado como hoje: não é fácil encontrar as portas das palavras não-ditas" (BAQUíLIDES apud ACHCAR, 1994, p. 13). Em ambos os casos, contudo, a ideia de que o discurso poético repisa outros chãos não parece autorizar a conclusão de que ele não valha a pena. Trata-se, na verdade, do fato de que "é sobretudo na utilização dos topoi que se revela a originalidade do poeta" (ACHCAR, 1994, p. 29).

Interpõe-se, portanto, entre os dois pontos de vista, uma experiência histórica que somente o poeta contemporâneo possui que é, por um lado, a confirmação factual da perenidade da poesia (já que deliberadamente poetas de hoje reescrevem um poema latino do século I a.C.) e, por outro lado, a experiência da exaustão de todo um século (o século $\mathrm{XX}$ ) que tomou para si a busca pelo novo como motivo condutor dos movimentos artísticos. Do seu ambíguo lugar de observação, o poeta contemporâneo parece preferir testemunhar a experiência da rápida obsolescência da palavra poética à sua imortalidade, inclinando-se, relativista, à decretação de sua inutilidade.

Henriques Britto é um poeta que não escamoteia sua adesão às formas tradicionais sem, contudo, deixar de praticar reflexão e tom contemporâneos em sua poesia. É o caso do soneto abaixo, sem divisão de estrofes, vazado em decassílabos e com esquema rímico definido em $\mathrm{abab} / / \mathrm{abab} / / \mathrm{abc} / / \mathrm{abc}$.

Tudo se perde, nada se aproveita, eu sei. Porém a impressão permanece:

alguma (pouca) coisa que foi feita pode talvez merecer uma espécie de não exatamente eternidade, mas mais que o imediato esquecimento. Será ilusão? Será pura vaidade? Bem provável. Sendo assim, me contento com o vago prazer (se é mesmo prazer) 
de rabiscar num caderno, ao acaso, o que talvez jamais venha a ser lido por mais ninguém. Nem por mim. Escrever é preciso. Por quê? Não vem ao caso.

E faz sentido? Não. Não faz sentido. (BRITTO, 2012, p. 16)

O poema "dialoga" frontalmente, por assim dizer, com o tema da perenidade da poesia, imortalizado por Horácio em sua ode, como deixa explícito o poeta no verso 5 ("de não exatamente eternidade"). Salta aos olhos, contudo, que o soneto de Britto não enuncia a mesma verdade que o poema que lhe serve de fonte, muito pelo contrário, submete a mensagem horaciana a uma série de suspeitas a ponto de pô-la em xeque.

Tal processo de contestação cética é o motivo condutor de todo o soneto que se abre e se encerra com duas afirmações aceitas pelo eu lírico comoúnicas verdades sobre as quais não incide nenhuma dúvida. São elas: "Tudo se perde, nada se aproveita" e "Não faz sentido". Com essas duas assertivas servindo como postulados explícitos do poema, tudo o mais que decorre nos 12 versos que preenchem o soneto são dúvidas e hesitações: "porém", "impressão", “alguma (pouca)", "talvez” (2 vezes), "não exatamente”, "será...?” (duas vezes), "provável”, "vago", "se é mesmo", "por quê?”.

Se considerarmos, portanto, que os dois postulados do poema são afirmações negativas, tudo o que o poema faz é bombardear de relativismos o otimismo horaciano para, finalmente, pô-lo em xeque. Muito embora, de maneira parecida à que ocorreu no poema "Circular", esse também tende a corroborar, duplamente, aquilo que é negado: em primeiro lugar por afirmar a perenidade da poesia, por se tratar de um poema escrito para falar de um poema milenar; em segundo lugar por persistir no alegado sem-sentido da escrita poética, alegação essa feita em um poema.

É de uma "recusatio irônica do topos clássico" (ACHCAR, 1994, p. 157) que se trata aqui, mais explícita, porém, do que a que Achcar aponta nos poemas do Drummond de Claro enigma e que também se verifica em outros momentos da poesia contemporânea. Há pelo menos mais outro registro explícito, na poesia brasileira, de atualização desse topos em abordagem irônica. Trata-se do poema intitulado exegi monumentum de autoria de Nelson Ascher, presente em seu livro Parte alguma. Cito-o de passagem: 
Ergui pra mim, mais alto que o Empire State Building, menos

biodegradável mesmo

que o urânio, um monumento

que, à chuva ácida ileso

e imune à inversão térmica, não tem turnover nem sairá de moda nunca.

Não morrerei de todo: cinquenta ou mais por cento de meu ego hão de incólumes furtar-se à obsolescência programada e hei de estar no Quem É Quem enquanto Hollywood dê seus Oscars anuais ou supermodels (ASCHER, 2005, p. 13).

Achcar nos lembra que o próprio Horácio havia praticado o que ele (o crítico brasileiro) chamou de uma "remodelagem genérica", ou seja, "a adaptação de matéria própria de um a outro gênero ou estilo [...] trata-se de passar do 'grande estilo' das odes que versam o tema, sobretudo exegi monumentum, para o modo rebaixado, 'desinflado' [...]" (ACHCAR, 1994, p. 182). Seguem trechos da tradução em prosa fornecida por Achcar do referido poema:

Pareces, livro, estar de olho em Vertuno e Jano, naturalmente para te expores polido pela pedra-pomes dos Socii. Odeias as chaves e os selos caros ao pudico; lamentas ser mostrado a poucos e louvas os lugares públicos, tu que não foste educado para isso. Anda, corre para onde anseias descer: não haverá retorno depois que tiveres partido. "Que fiz eu, infeliz? Que desejei?” dirás quando sofreres alguma afronta, e sabes que ficarás restrito a um canto, quando o amante enlanguescer, saciado. [...] quando, apalpado pelas mãos do vulgo, começares a te estragar, ou taciturno apascentarás as lentas traças [...]. Este destino também te espera: que te colha a velhice balbuciante quando estiveres ensinado abecê aos meninos, em lugares distantes [...] (HORÁCIO apud ACHCAR, 1994, p. 181). 
A mensagem do poema é, claramente, a mesma que consta em dois momentos da famosa Carta aos Pisões em que o poeta latino recomenda enfaticamente que o poema precisa ser retido por longos nove anos e, durante todo esse tempo, deve ser limado, riscado e submetido à crítica dos mais experientes para, só então, ser publicado, pois a palavra lançada não tem mais volta. Cito os trechos da referida carta em tradução em versos de Cândido Lusitano (Francisco José Freire) que consta na primorosa recolha de poéticas clássicas organizada por Roberto Acízelo de Souza:

Se não custasse tanto a nós poetas

Os escritos limar, como o guardá-los

Por longo tempo. Ó vós de numa estirpe,

Repreendei todo aquele que não sabe

Muitas vezes riscar o seu poema,

Nem sepultá-lo em si por longos dias,

E dez vezes limá-lo, até que chegue

A dar-lhe o mais perfeito polimento.

(HORÁCIO, 2014, p. 97).

[...] mas se acaso

Houveres de compor, ouve a sentença

De Mécio, de teu pai, e também a minha.

Nove anos encerrado esteja o livro;

Porque, enquanto o estiver, podes limá-lo;

Mas público uma vez, não tem emenda:

Voz, que se proferiu, foi-se, e não torna.

(HORÁCIO, 2014, p. 103).

Se considerarmos, com Achcar, que é da mesma matéria que tratam os dois exemplos, forçoso é considerar, por sua vez que, apesar da diferença na modelagem, ambos os poemas advogam em nome da mesma causa ou, dito de outro modo, direcionam-se rumo a uma mesma mensagem. Isso porque, no caso do registro rebaixado, se o que se censura é o livro que se lançou prematuramente ao público, é justamente por não ter atendido às exigências necessárias (prescritas, como se viu, na Arte Poética horaciana) que ele não logrou status de verdadeira poesia e que, portanto, só pode ter o destino nada digno que lhe foi antevisto. Nesse sentido, o referido rebaixamento não representa uma derrisão da mensagem original do exegi monumentum mas, ao contrário, um reforço dela. 


\section{Referências}

ACHCAR, F. Lírica e lugar-comum: alguns temas de Horácio e sua presença em português. São Paulo: Edusp, 1994.

AGAMBEN, G. O que é o contemporâneo? e outros ensaios. Tradução de Vinícius Nicastro Honesko. Chapecó: Argos, 2009.

ARISTÓTELES. Poética. In: ARISTÓTELES; HORÁCIO; LONGINO. A poética clássica. Tradução de Jaime Bruna. São Paulo: Cultrix, 1981.

ASCHER, N. Parte alguma (1997-2004). São Paulo: Companhia das Letras, 2005.

BRITTO, P. H. Formas do nada. São Paulo: Companhia das Letras, 2012.

CURTIUS, E. R. Literatura europeia e Idade Média latina. Tradução de Teodoro Cabral. São Paulo: EDUSP, 2013.

HOMERO. Ilíada. Tradução de Haroldo de Campos. São Paulo: Arx, 2003.

HORÁCIO. Arte poética. Tradução de Cândido Lusitano. In: DE SOUZA, R. A. (Org.). Do mito das musas à razão das letras. Textos seminais para os estudos literários (século VIII a.C.-século XVIII). Chapecó: Argos, 2014.

HORÁCIO. Odes e epodos. Tradução de Bento Prado de Almeida Ferraz. São Paulo: Martins Fontes, 2003.

HOUAISS, A. Dicionário eletrônico da língua portuguesa. Versão 3.0. São Paulo: Objetiva, 2009. 1 CD-ROM.

HUTCHEON, L. Poética do pós-modernismo: história, teoria, ficção. Tradução de Ricardo Cruz. Rio de Janeiro: Imago, 1991.

MARQUES, Fabrício. Ficando tarde. In: DANIEL, C.; BARBOSA, F. (Org.). Na virada do século. Poesia de invenção no Brasil. São Paulo: Landy, 2002.

MOISÉS, C. F. O desconcerto do mundo. Do Renascimento ao Surrealismo. São Paulo: Escrituras Editora, 2001.

NOGUEIRA, E. O livro de Scardanelli. São Paulo: É realizações, 2008.

SANT'ANNA, A. R. de. Intervalo amoroso e outros poemas escolhidos. Porto Alegre: L\&PM, 1999. (L\&PM Pocket).

SPINA, S. Do formalismo estético trovadoresco. São Paulo: Ateliê Editorial, 2009. 